\title{
Augmented Reality Technology in Handball Teaching Based on Wireless Communication Environment
}

\section{Qin Fan}

Anhui University of Fiance and Economics

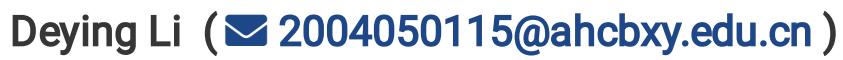

Anhui Vocational College of Press and Publishing

\section{Research}

Keywords: Wireless Communication, Augmented Reality, Handball Events, Intelligent Teaching

Posted Date: January 1st, 2021

DOl: https://doi.org/10.21203/rs.3.rs-137963/v1

License: (c) (1) This work is licensed under a Creative Commons Attribution 4.0 International License.

Read Full License 


\title{
Augmented Reality Technology in Handball Teaching Based on Wireless Communication Environment
}

\author{
QinFan $^{1, \mathbf{a}}$ and DeyingLi ${ }^{2, \mathbf{b}^{*}}$ \\ ${ }^{1}$ Physical Education Department, Anhui University of Finance and Economics, Bengbu 233041, \\ Anhui, China \\ ${ }^{2}$ Basic Department, Anhui Vocational College of Press and Publishing, Hefei 230601, Anhui, China \\ a120081598@aufe.edu.cn \\ b2004050115@ahcbxy.edu.cn \\ *Corresponding author
}

\begin{abstract}
With the popularization of augmented reality technology in the field of teaching, the development from traditional teaching display to classroom application has greatly promoted the information-based teaching work. The work of this study is to use augmented reality technology in a wireless communication environment to apply to handball guidance. In this study, 13 handball teachers (coaches) and 103 student athletes were selected as subjects from seven traditional handball schools in our state. All subjects were tested in the Kolb learning style test scale (klsi 1985). It is divided into four groups: group A, group B, group C, and group D, depending on the various learning styles. These correspond to type of variance, type of assimilation, type of convergence, and type of adaptation. In this study, experimental staff were divided into two groups: a traditional learning control group and an experimental group of AR technology education. The results show that the improvement value of the experimental group before and after learning is 8.65 , while that of the control group is 5.625. In terms of knowledge and skills, process and method, and emotional attitude, the use of AR makes assimilative and convergent learners have better learning performance than decentralized and adaptive learners. The conclusion is that the effect of augmented reality technology under wireless communication is excellent and effective in handball teaching. This study provides a new method for intelligent teaching.
\end{abstract}

Keywords: Wireless Communication, Augmented Reality, Handball Events, Intelligent Teaching

\section{Introduction}

Training young people's sports ability is the basis to ensure the existence and development of competitive sports, and plays an important role in the sustainable development strategy of Chinese sports. Handball has always been the main sports tradition of Anhui schools. Handball changes frequently and suddenly in various skills, unpredictable tactics, attack and defense, and the combination of attack and defense technology and tactics, the relationship between technology and technology has been adjusted and consistent. The game is very exciting, very interesting, sports value is very high, in these sports schools in China to lay a deep foundation. Modern handball is characterized by strong groups, fierce confrontation, high intensity, fast speed and strong skills. The complex and changeable tactical characteristics are supported by more and more young people in the school.

The interactive technology features of extensively relativistic technology provide the learner with virtual learning environments, learner's imagination and creativity, and the conditions for educators to create advanced information education environments and diverse educational methods. Build a new educational platform to realize educational innovation and exchange. Extended relational technology provides an intuitive and interactive exploration learning environment for research learning, and plays 
an important role in creating educational situations and enhancing classroom education. Exploring applicable ways to expand practical skills in the field of education and opening windows in technology applications in the field of education is an integral part of the educational reform supported by technology.

In the research of handball and augmented reality technology teaching, Ramos A studies team handball (th) as a new and innovative teaching activity. Although this is not a new activity, it is largely unknown to many students in the United States. In his approach, students have the opportunity to experience and learn basic motor and manipulation skills. In addition, players can usually run for an hour in the heart function of the heart. Like most competitions, it helps students develop their decision-making and problem-solving skills. His method is not accurate enough [1]. The purpose of Fruchart E's study was to compare 216 young handball players of different ages with five different information cues (consequence of attack, current score, remaining game time, background of aggression, and relative importance of the game) to determine to what extent a player's aggressive behavior in handball matches can be calculated. Participants showed their judgment in 48 scenarios composed of these information clues. His method was used for cluster analysis, and he observed two different positions of moral judgment. His method is too subjective [2]. Demitridou E uses virtual reality and augmented reality technology to visualize 3D objects. They studied the potential of using virtual and augmented reality technology in primary school geometric entity classes. As part of the study, he divided 30 primary school students into three groups, including a control group and two experimental groups. The first and second experimental groups used specialized virtual and augmented reality applications to learn geometric entities, while students in the control group used traditional printed materials as part of the learning process. His method is not practical enough [3]. The purpose of this study is to explore the effect of augmented reality (AR) - supported geometry teaching on students' three-dimensional thinking ability. His research includes three steps: the development of three-dimensional thinking ability scale; the design and development of AR geometry tutorial system (argts); and the implementation and evaluation of geometry teaching supported by argts. He developed the three-dimensional thinking ability scale and tested the experimental group and the control group as the evaluation before and after the test. In order to improve the ability of 3D thinking, he developed an AR geometry tutorial system and AR teaching materials and environment. His method is not stable [4].

This study first introduces the main technologies of augmented reality display technology, tracking registration technology and human computer interaction technology. At the same time, it also explains three realization methods of extending reality technology and the function of physics education. The algorithm of this study is mainly the extended reality technology of high precision automatic registration and coordinate exchange in extended reality. The survey selected some handball players and coaches in the state as the survey subjects, using AR technology and other handball education. The effectiveness of this research on the novelty and effectiveness of handball education can be greatly improved.

\section{Methods}

\subsection{Key Technologies of Augmented Reality}

(1) Display technology

Augmented reality application refers to optical path imaging techniques between the user's eye and the actual environment, specifically designed for human vision. The virtual information output is a 3D model or graphics. Therefore, expansion technology is one of the most important technologies. In 
general, augmented reality display technology is divided into mobile mobile handheld displays, video space displays, Spatially Augmented reality displays, wearable displays. The mobile handheld display used in this study mainly refers to learners who use smart phones, extends real-time viewfinder of real time applications to scan and identify objects, and digital information and screen overlays Point the pushpoint. This is the operating condition of the mobile handheld display [5-6].

(2) Tracking registration technology

In augmented reality system, tracking and registration are the technical basis of building extended reality system, which is also the main technical difficulty. Tracking and registration technology is the focus of extended reality system research. Tracking and registration accuracy is an important index to measure the performance of extended reality system and affect its practicability. In order to realize the seamless combination of real environment and virtual information, virtual information must be displayed in the correct position in the real world. This important process is called registration. According to the observer's current field of view, the coordinate system is reestablished and the virtual object is displayed in the following ways. This process to the correct position is called tracking [7-8].

(3) Human computer interaction technology

In the early research of augmented reality technology, the focus of research is tracking, registration and display. Virtual objects are simply overlapped in the actual scene, and they do not interact with the outside world. They only display the virtual effects and actual effects through the display device. The interaction between real information and system is realized. The extended reality system tracks and locates the equipment to obtain the data, determines the action instructions issued by the user to the virtual object, explains, provides the corresponding correct feedback, and realizes the human computer interaction technology in an effective way [9].

\subsection{Implementation of Augmented Reality Technology}

(1) Professional software

ARToolKit, coin 3D, mrplaatform has many software based on augmented reality technology. Many companies in Japan and abroad are conducting research in this field. Domestic companies such as Intranet technology, antenna technology, and WIA video have developed augmented reality technology software. Ar professional software supports image recognition, location capture, automatic $3 \mathrm{D}$ registration and other technical features [10].

(2) Network terminal

With the development of computers and communication technologies, networked augmented reality technology is the key direction of development. The application of the network can effectively reduce the cost of the equipment and expand the application space of the system. An augmented reality web program based on flash technology was developed [11-12].

(3) Mobile terminal

Mobile terminal is the development trend of AR application. Compared with desktop extended reality system, mobile extended reality system has obvious differences in technical environment, display device and tracking technology, and its application program is flexible and easy to use. The main technologies of mobile augmented reality include sensor technology, display technology and 3D registration technology [13-14].

\subsection{The Role of Physical Education Technology in Enhancing the Reality of Teaching}

(1) Innovating sports demonstration activity way, endowing technical action with more vigor

In the case of sports demonstration based on augmented reality technology, this demonstration 
method is also an independent innovation, which needs to be given vitality through sports technical action. Let students have a deeper understanding of knowledge. This can not only effectively mobilize students to participate, but also more effectively cultivate students' jumping ability and ability[15].

(2) Reflect the multimedia display of physical education teaching content

Sports demonstration based on augmented reality technology needs to make full use of all kinds of photos and videos in physical education and pay attention to working conditions to supplement the technical advantages of multimedia. Seriously implement the venue, coaches, funds, equipment, etc. Under the background of the expansion of university enrollment, the number of students is increasing, the existing sports facilities can not meet the needs of College Students' extracurricular sports, volleyball activities are limited to a certain extent. From the perspective of volleyball education, the venue and equipment of our school can not fully meet the needs of the class and students [16-17].

(3) Reasonable arrangement of volleyball teaching content and improvement of curriculum system

With the continuing improvement of educational reform, the increase in sports, and the shortening of the learning time, teachers need to be reasonably improving their educational content so that students can "study well" in a short time without teacher's guidance [18-19].In the third stage of strengthening tactical education and practice, students can organize their own competitions to develop organizational skills and use techniques and tactics in a more standardized manner. From the perspective of theory and theory, it can improve the ability to use technology and tactics, but it also affects the learning of technology. Teachers need to find and correct problems within time [20].

(4) Create a strong atmosphere of school volleyball

Schools need to provide students with the necessary equipment to create a good state. In order to promote the development and popularization of volleyball, we should adopt face-to-face approach, provide extracurricular guidance for students, and take effective measures to mobilize students' enthusiasm. Update ideas and develop multi-level and multi form volleyball matches [21-22].

\subsection{High Precision Automatic Registration of Augmented Reality}

(1) Image coordinate system

Depending on the size of the image, a 2-pixel (pixel) coordinate system establishes a coordinate system. This is primarily based on the (x,y) coordinate system. In this image, the center point of the center of the camera is the origin, and the $\mathrm{X}$ axis coordinate axis is parallel to the physical axis of $\mathrm{u}$, and the axis of Y pixel is parallel to the physical axis of $\mathrm{v}$. The coordinate system of the physical size mainly focuses on the main optical axis of the camera and the focus of the image plane, the $\mathrm{X}$ axis and the $\mathrm{U}$ axis are flat in the same direction, and the $\mathrm{Y}$ axis is in the same direction. Axis direction and $\mathrm{V}$ axis are consistent [23-24]. Parallel. As shown in Figure 1, the image coordinate system in photogrammetry and computer vision.

(2) Exchange of image coordinate system and camera coordinate system

In this paper, the camera's first encounter after obtaining the image is the $(\mathrm{U}, \mathrm{V})$ coordinate system of the actual space image. The camera coordinate system has $\mathrm{x}$ axis, $\mathrm{Y}$ axis, and $(\mathrm{x}, \mathrm{y})$ coordinate system. In the coordinate system, the image can be transformed into coordinate system. The transformation from $(\mathrm{U}, \mathrm{V})$ to $(\mathrm{x}, \mathrm{y})$ coordinate system.

$$
\left\{\begin{array}{l}
x=(u-c x) * d x \\
y=(v-c y) * d y
\end{array}\right.
$$

$(\mathrm{x}, \mathrm{y})$ coordinates are converted to camera coordinates 


$$
\left\{\begin{array}{l}
X_{c}=x \\
Y_{c}=y \\
Z_{c}=-f
\end{array}\right.
$$

It can be seen from the above that $\mathrm{CX}$ and $\mathrm{CY}$ are the vertical foot points of the center point of the camera on the image plane, and the coordinates of the (U, V) coordinate system, DX and Dy are the physical sizes of the image pixels in the $\mathrm{X}$ direction and $\mathrm{Y}$ direction respectively. According to the collinear theory of camera center point, image point and object point in the central projection model, the relationship between the two points is derived.

$$
\left\{\begin{array}{l}
X_{c}=x * \lambda \\
Y_{c}=y * \lambda \\
Z_{c}=-f * \lambda
\end{array}\right.
$$

(3) Transformation between camera coordinate system and world coordinate system

$$
\left[\begin{array}{l}
X_{w} \\
Y_{w} \\
Z_{w}
\end{array}\right]=R\left[\begin{array}{l}
X_{c} \\
Y_{c} \\
Z_{c}
\end{array}\right]+T
$$

$\mathrm{XW}, \mathrm{YW}$ and $\mathrm{ZW}$ are the corresponding coordinates of the world coordinate system during the experiment, while $\mathrm{Xc}, \mathrm{YC}, \mathrm{ZC}$ are defined as the camera coordinate system coordinates in the experiment process, where $\mathrm{R}$ is the rotation matrix between the two coordinate systems, and $\mathrm{t}$ is the displacement relationship between the camera coordinate system and the world coordinate system. Both $\mathrm{R}$ and $\mathrm{T}$ are external parameters of the camera, which are obtained by camera calibration or action recovery structure of multi view images. When the computer vision system is implemented, the transformation relationship described by $\mathrm{R}$ matrix and $\mathrm{T}$ matrix is completely opposite to that of photo measurement [25].

$$
\left[\begin{array}{l}
X_{c} \\
Y_{c} \\
Z_{c}
\end{array}\right]=R\left(\left[\begin{array}{l}
X_{w} \\
Y_{w} \\
Z_{w}
\end{array}\right]-T\right)
$$

\subsection{Transformation between Two Coordinate Systems}

(1) Principle of spatial mapping transformation

When registering the coordinate system, two different coordinate systems must be used to measure the coordinates of the same common point set, and the postures of the two coordinate systems are associated through the common coordinate set. Firstly, several marked points are selected in the actual space, and any marked point $\mathrm{A} 0$ is selected as the origin of the reference coordinate system. $\mathrm{A} 0$ and the other three coordinate points $\mathrm{A} 1, \mathrm{~A} 2$ and $\mathrm{A} 3$ are connected to establish the $\mathrm{x}$-axis, Y-axis and $\mathrm{z}$-axis. Then, set the vector $\overrightarrow{A_{0} A_{1}}, \overrightarrow{A_{0} A_{2}}, \overrightarrow{A_{0} A_{3}}$ as the unit vector on their respective axes, so that the coordinates of $\mathrm{A} 0, \mathrm{~A} 1, \mathrm{~A} 2$ and $\mathrm{A} 3$ are $(0,0,0),(1,0,0),(0,1,0),(0,0,1)$. In this way, the position $A_{p}\left(x_{p}, y_{p}, z_{p}\right)$ of any point in the operation space can be uniquely determined, which satisfies the following formula: 


$$
\overrightarrow{A_{0} A_{p}}=x_{p} \overrightarrow{A_{0} A_{1}}+y_{p} \overrightarrow{A_{0} A_{2}}+z_{p} \overrightarrow{A_{0} A_{3}}
$$

The space mapping between unity $3 \mathrm{~d}$ space and actual operation space is converted into rigid transformation (including parallel movement and rotation). The space mapping transformation of two coordinate systems can be completed by using the transformation matrix. $\mathrm{R}$ is a $3 \times 3$ rotation matrix and $t$ is $3 \times 1$. The mapping matrix of transformation matrix $T$ from real space to unity $3 \mathrm{~d}$ space is as follows:

$$
T=\left[\begin{array}{l}
x_{a 1}-x_{0}, x_{a 2}-x_{0}, x_{a 3}-x_{0}, x_{0} \\
y_{a 1}-y_{0}, y_{a 2}-y_{0}, y_{a 3}-y_{0}, y_{0} \\
z_{a 1}-z_{0}, z_{a 2}-z_{0}, z_{a 3}-z_{0}, z_{0} \\
0,0,0,1
\end{array}\right]=\left[\begin{array}{l}
R, t \\
0,1
\end{array}\right]
$$

In this way, a one-to-one correspondence relationship is established between the real space and the coordinates of the marker points in the virtual space. Each virtual body PX in the virtual space can be uniquely mapped to the corresponding position entity PS on the human organs in the real space, which is converted into:

$$
P_{s}=T^{-1} * P_{x} ; P_{x}=T * P_{s}
$$

(2) Obtaining the center point of human organ bounding box in real space

The non orthogonal coordinates PNO of the rest points on the manikin in unity $3 \mathrm{~d}$ are calculated by taking the four marked points PX as the base coordinates. The center point coordinates PS of the bounding box of human organs in real space coordinate system are obtained.

$$
p_{0}=\left|\begin{array}{c}
p_{s 1}-p_{s 0} \\
p_{s 2}-p_{s 0} \\
p_{s 3}-p_{s 0}
\end{array}\right| *\left|\begin{array}{l}
P_{\text {No.x }} \\
P_{\text {No.y }} \\
P_{\text {No.z }}
\end{array}\right|+\left|\begin{array}{c}
p_{s 0} \cdot x \\
p_{s 0} \cdot y \\
p_{s 0} \cdot z
\end{array}\right|
$$

(3) Angle conversion between coordinates

The rotation matrix $\mathrm{R}$ obtained by spatial mapping can be used to calculate the rotation matrix between real human organs and virtual human organs. Through the transformation between rotation matrix and Euler angle, the rotation angle of human organs relative to the actual human organs around model YXZ can be obtained.

$$
\begin{array}{r}
R_{1}=R_{y} * R_{x} * R_{z}=\left|\begin{array}{l}
\cos _{b} \cos _{h}+\sin _{b} \sin _{p} \sin _{h} ; \sin _{b} \cos _{p} ; \cos _{b} \sin _{h}+\sin _{b} \sin _{p} \cos _{h} \\
-\sin _{b} \cos _{h}+\cos _{b} \sin _{p} \sin _{h} ; \cos _{b} \cos _{p} ; \sin _{b} \sin _{h}+\cos _{b} \sin _{p} \cos _{h} \\
\cos _{p} \sin _{h} ;-\sin _{p} ; \cos _{p} \cos _{h}
\end{array}\right| \\
M=\left|\begin{array}{c}
m_{11}, m_{12}, m_{13} \\
m_{21}, m_{22}, m_{23} \\
m_{31}, m_{32}, m_{33}
\end{array}\right|=R_{y} * R_{x} * R_{z}=R_{1}
\end{array}
$$

In the left-handed system, the matrix RX corresponding to the rotation angle $\mathrm{P}^{\circ}$ about the $\mathrm{x}$-axis

$$
p=\alpha \sin \left(-m_{32}\right)
$$

In the left-handed system, the matrix ry corresponding to the rotation angle $\mathrm{h}^{\circ}$ about the $\mathrm{Y}$ axis 


$$
h=\alpha \tan 2\left(\frac{m_{31}}{\cos _{p}}, \frac{m_{33}}{\cos _{p}}\right)
$$

In the left-handed system, the matrix RZ corresponding to the rotation angle of $\mathrm{B}{ }^{\circ}$ around the $\mathrm{z}$-axis is

$$
b=\alpha \tan 2\left(\frac{-m_{12}}{\cos _{p}}, \frac{m_{22}}{\cos _{p}}\right)
$$

\section{Handball Teaching Model of Augmented Reality Technology}

\subsection{Research Object}

The subject of this paper is the present state of handball in the traditional schools of our state. There are 13 handball teachers (coach) and 103 student athletes in our seven traditional handball schools.

\subsection{Preparation of AR Experimental Tools}

Join a software. Revitstructure? Revitstructure? A customized building information modeling (BIM) solution for structural engineering companies with powerful tools for structural design and analysis. In this experiment, revitstructure was used to explain the enhancement of the joints. B. 3dmax3 Dmax is a carefully developed PC based 3D animation rendering and production software. In this study, the 3DMAX to configure the node file in the AR application? 3DMAX is used to convert the file format exported by the revitstructure while performing the necessary rendering process in the node file. C. ARToolKit? ARToolKit is a program library written in $\mathrm{C} / \mathrm{C}++$ language and can easily describe AR applications. The survey uses an AR application developed by the previous survey based on AR Toolkit.

\subsection{Reliability Test}

Retest method: the specific method is to ask four handball teachers (coaches) from Haifei No.3 middle school and Anhui handball psychological school, and 30 players from Haifei No.3 middle school and Kaike middle school in huaibingwei city to fill in the questions. After three weeks, they repeated the same question and calculated the correlation coefficient R. According to the calculation, the correlation coefficient of the two results before and after the coach question table is $\mathrm{r}=0.722, \mathrm{P}<$ 0.01 , which indicates that the result of the coach question table is reliable. The correlation coefficient of the two results before and after the athletes fill in the question form shows that $\mathrm{r}=0.713, \mathrm{P}<0.01$, and the investigation results of athletes are reliable.

\subsection{Setting of Learning Effectiveness Evaluation Method}

According to the completeness of the educational goals, Broome, a well-known American educational psychologist, has formulated a classification system for educational goals. Combining broom's educational purpose classification theory and Chinese education and education practices, Chinese scholars believe that educational objectives are three levels of knowledge, skills, processes and methods, emotions, attitudes and values, knowledge and skills. D goal. In this experiment, three dimensional tests and questionnaires were set in order to examine the learning purpose of three dimensions and to analyze the learning effect of the learner according to the three-dimensional educational purpose. In these three dimensions, knowledge and skills, processes and methods, emotions, attitudes and values. 


\subsection{Experimental Process}

Subjects in each learning style group were randomly divided into two groups. The groups A1, B1, $\mathrm{C} 1$, and D1 first learned and answered questions through the previous paper data, and then answered the questions through ar data A2, B2 and C2. And the D2 group was against. At the same time, in order to avoid such mistakes, the author prepared two very difficult teaching materials and a test questionnaire, and introduced the purpose and main contents of the experiment to the subject, and introduced basic information of the learning material. At the same time, in order to explain the specific requirements of the experiment and ensure the correctness of the experimental data, the experimental subjects need to complete the test independently in the experiment, and can not exchange answers with other people.

\section{Handball Teaching Based on Augmented Reality Technology}

\subsection{Basic Situation Analysis of Handball Players}

(1) Age analysis of handball players

According to the analysis, $30 \%$ are $12-13$ years old, $40 \%$ are $14-15$ years old, and 30\% are 16-17 years old. From this we can see that there are many young handball players aged 14 to 15 in this state, and their age distribution is relatively uniform. From the perspective of age group, anheyi County attaches great importance to young handball players, and the acceptance of negligence among age groups is not obvious. As shown in Table 1, athletes engaged in sports training time statistics.

Table 1. Time statistics of athletes engaged in sports training

\begin{tabular}{ccc}
\hline Training time & Frequency (Times) & Percentage $(\%)$ \\
\hline More than 5 years & 7 & $6.1 \%$ \\
\hline $1-5$ years & 75 & $72.6 \%$ \\
\hline Less than 1 year & 21 & $21.3 \%$ \\
\hline
\end{tabular}

As shown in Figure 2, athletes' motivation statistics of sports training.

It can be seen from Table 1 and Figure 2 that among the handball school players surveyed, 21 athletes had less than one year's training, accounting for $21.1 \%$ of the total, and 82 athletes had been trained for more than one year. $78.8 \%$ of the total population. According to the survey of 103 handball players from handball school, 57 (35.2\%) chose their hobbies, 44 (27.2\%) became excellent players and 40 chose their own. The coach found that his talent accounted for $24.7 \%, 18$ people chose to take the exam, $11.1 \%$ from his family, and $1.8 \%$ from 3 people who chose others. Athletes are basically out of personal interest and interest. This shows that the student athletes have a strong interest and a clear goal.

(2) Site and facilities of traditional handball events

The survey results show that $14 \%$ of the schools have two training venues, $43 \%$ have one training venue and $42 \%$ have no training venue. As shown in Figure 4, 46\% of the coaches think that the quality of the training ground is average, $23 \%$ of the coaches think the training ground is better, and $23 \%$ of the coaches think that the training ground is not good or not. This shows that in order to meet the need of training, schools should continue to increase the investment in the construction of training ground. The facilities of Anfu traditional handball school should be further improved in quantity and quality. A good training place is a necessary condition to ensure the training of sports teams. As shown in Table 2, the statistics of the number of training sites. 
Table 2. Statistics of the number of training sites

\begin{tabular}{ccccc}
\hline Outdoor & Nothing & One & Two & More than 3 \\
\hline $\begin{array}{c}\text { Frequency } \\
\text { (Times) }\end{array}$ & 3 & 3 & 1 & 0 \\
\hline \begin{tabular}{c} 
Percentage $(\%)$ \\
\hline
\end{tabular} & $44 \%$ & $47.1 \%$ & $14 \%$ & 0 \\
\hline
\end{tabular}

As shown in Figure 3, the quality statistics of training sites.

From Figure 3, it can be seen that the training place of handball players is generally concentrated in the outdoor handball training field, while physical training is generally conducted in the track and field. According to the survey data, traditional handball school handball physical training field is not very attention. Having comprehensive physical strength is the basis of learning handball skills. Pay attention to the comprehensive physical strength needed to improve the development of body balance, and lay a foundation for improving the specific strength of handball. In the overall training consideration, the first is to strengthen the physical strength. Through the comprehensive fitness foundation, we can endure a lot of sports and comprehensive physical training after adults.

\subsection{Basic Performance of Experimental Data}

The results showed that one in group $\mathrm{C}$ did not meet the requirements of group $\mathrm{C}$ and 3 did not meet the requirements of group C. After excluding two invalid experimental data, 33 effective experimental data were obtained. As shown in Table 3, the number of subjects was counted.

Table 3. Statistics of the number of subjects

\begin{tabular}{ccccc}
\hline & Dispersive type & Assimilator & Converger & Adaptive type \\
\hline General teaching & 4 & 4 & 5 & 5 \\
\hline VR Teaching & 4 & 3 & 4 & 4 \\
\hline total & 8 & 7 & 9 & 9 \\
\hline
\end{tabular}

As shown in Figure 4, the experimental overview.

\subsection{Effectiveness of Handball Teaching in AR Technology}

The values of learning can make learners identify and improve their emotions. Relatively speaking, the recognition degree of adaptive learners will be reduced. Emotional attitude and values can be divided into three aspects: emotion, attitude and values. Among them, emotion refers to the concern for learning, learning enthusiasm, learning enthusiasm, etc.; attitude refers to learning attitude, learning responsibility, realistic scientific attitude, etc.; value requires long-term learning experience, so this research does not include the investigation and analysis in this field. As shown in Figure 5, the radar chart of teaching effectiveness.

From the radar chart of teaching effect in Figure 5, it can be seen that in terms of knowledge and skills, process and method, as well as emotional attitude, the assimilation and aggregation of learners can achieve learning results compared with dispersed and adaptive learners. There is a better improvement.

In addition, according to the content feedback of the short answer of the subjective survey paper (i.e. the advantages and disadvantages of traditional education methods and AR education methods), learners generally think that the paper textbooks are too intuitive and abstract, but the equipment requirements are low and easy to read. The guidance method of AR is intuitive, easy to understand, high participation, easy to stimulate learners' interest in learning, but the equipment requirements are high. In addition, some learners think that compared with the easy to understand AR, the paper textbook is easier to let learners play their spatial imagination. Some learners also suggest that it is 
necessary to combine AR and paper textbooks to make the advantages of the two learning materials compatible.

(1) Significance test

The experimental data were classified according to the process and method, emotional attitude and values. The score data of each test object's question table was summed up according to each dimension, and the average value of each test object in each dimension was calculated. After that, SPSS software was used to perform one-way decentralized analysis. As shown in Table 4, the basic analysis of learning effectiveness data.

Table 4. Basic analysis of learning effectiveness data

\begin{tabular}{cccccc}
\hline & $\begin{array}{c}\text { Average } \\
\text { Value }\end{array}$ & $\begin{array}{c}\text { Standard } \\
\text { Deviation }\end{array}$ & Error & $\begin{array}{c}\text { Minimum } \\
\text { Value }\end{array}$ & Maximum \\
\hline 1 & 4.179 & 0.476 & 0.169 & 3.44 & 4.58 \\
\hline 2 & 4.164 & 0.463 & 0.175 & 3.44 & 4.58 \\
\hline 3 & 4.540 & 0.397 & 0.133 & 4.01 & 5.01 \\
\hline 4 & 3.731 & 0.315 & 0.105 & 3.15 & 4.15 \\
\hline total & 4.152 & 0.497 & 0.087 & 3.15 & 5.01 \\
\hline
\end{tabular}

As shown in Figure 6, knowledge and skills learning is effective.

As can be seen from Figure 6, the unidirectional ANOVA test has been implemented. The importance of the combination of learning styles in process and method, emotional attitude and values is less than 0.05. Therefore, learning style can be seen as having a great influence on process and method, emotional attitude and values. In other words, if the learners use AR to learn, the subjective evaluation such as learning process and method, learning interest, learning enthusiasm, learning attitude, learning responsibility and scientific attitude will vary with learning style.

\subsection{Handball Teaching Test of Augmented Reality Technology}

In order to evaluate the learning effect quantitatively, this experiment summarized the handball test which designed the learning content. There are 30 questions in the exam, and the total score is 30. The content of the examination is handball knowledge. The experimental group and the control group carried out pre test and post test respectively. Test scores are used to measure handball proficiency. Before and after the experiment, 40 questionnaires were distributed and 80 effective test papers were collected. According to the collected data, the test scores of the experimental group and the control group were paired to test t. The main analysis results are shown in Table 5.

Table 5. Paired t-test table of test results before and after the experiment

\begin{tabular}{cccccc}
\hline & $\begin{array}{c}\text { Number of } \\
\text { samples }\end{array}$ & $\begin{array}{c}\text { Learning } \\
\text { style }\end{array}$ & $\begin{array}{c}\text { Pretest } \\
\text { results }\end{array}$ & $\begin{array}{c}\text { Post test } \\
\text { results }\end{array}$ & $\begin{array}{c}\text { Standard } \\
\text { deviation }\end{array}$ \\
\hline $\begin{array}{c}\text { Experience } \\
\text { group }\end{array}$ & 20 & AR & 12.66 & 21.31 & 0.75 \\
\hline $\begin{array}{c}\text { Control } \\
\text { group }\end{array}$ & 20 & $\begin{array}{c}\text { Traditional } \\
\text { learning }\end{array}$ & 12.18 & 17.82 & 0.51 \\
\hline
\end{tabular}

As shown in Figure 7, the experimental results are compared.

From the information in Table 5 and Figure 7, it can be seen that handball knowledge knowledge is improving after learning, which has nothing to do with the previous classroom education methods and the use of handball education software to expand the basis of real technology. According to the results of t-test analysis, the improvement value of the experimental group before and after learning is 
8.65 points, and according to the previous learning methods, the improvement value of the contrast group before and after learning is 5.625 points. Because of the difference in the score increase of the two learning methods, in this paper, the learning method is taken as the influencing factor, and the independent sample $t$ test is performed on the score data of the experimental group and the control group after the test. As shown in Table 6, the independent sample t-test of post-test results.

Table 6. Independent sample t-test of posttest results

\begin{tabular}{|c|c|c|c|c|c|c|}
\hline & $\mathrm{F}$ & Sig & $\mathrm{t}$ & df & Difference & error \\
\hline $\begin{array}{c}\text { Variance } \\
\text { equal }\end{array}$ & 0.396 & 0.017 & 50197 & 39 & 350000 & 0.674 \\
\hline $\begin{array}{l}\text { Variance } \\
\text { inequality }\end{array}$ & & & 3.198 & 31406 & 350000 & 0.674 \\
\hline
\end{tabular}

From Table 6 , the $\mathrm{p}$ value of validity is 0.016 , which is smaller than the effectiveness value of 0.05 . Technology can be enhanced, but technology can be improved. From the statistical point of view, although the results of experimental group and contrast group have been improved, there are significant differences between the two groups. The experimental data analysis results show that, compared with the previous learning methods, the handball knowledge and technology software based on extended reality technology will be more effective through the great changes in performance and the improvement of learning efficiency.

\section{Conclusion}

Virtual reality technology synthesis education

This study shows the prospect of extended reality technology in educational application at the level of theoretical construction and practical application, and systematically illustrates the value of education from the perspective of educational application strategy and educational model. With the development of real technology, the technical performance will be more mature. Using practical technology to teach applications has great potential. In the future education, extended reality technology will be integrated into our educational activities in a simpler and more intelligent way.

Teachers guide students in handball tactics

Teachers can use game exercises and educational conferences to let students act as judges. In this way, students can apply what they have learned and improve their ability to use techniques and tactics. According to this, students' organizational ability and practical work skills are developed, and students can experience in the conference. Teachers will organically combine technical and tactical guidance with the training of students' ability, actively think about the relationship and change between handball skills and tactics, guide students to learn, and achieve the purpose of training students' sports skills.

The impact and change of reality and virtual technology on education

Pure static two-dimensional text and images improve the original education and education methods. By expanding the learning of real education software, the interaction of culture, immersion and nature of learning media can be broken through, and the learners' interest is enhanced. Through the expansion of reality education software, learners can better learn knowledge and skills, and enter into life practice. In the real environment, the educational content can be displayed intuitively and stereoscopically, and the content structure can be arranged flexibly. Moreover, the extended reality model is a phenomenon that can be seen by transferring the knowledge learned by learners to the living environment. While establishing the relationship between the knowledge learned and the real life, it helps to internalize the learned knowledge, improve the ability of knowledge system to analyze and solve problems, and form a part of experience. 


\section{Results and Discussion}

This paper introduces several typical pilot frequency structures in wireless communication systems, and analyzes the characteristics of various pilot frequency structures. On this basis, the pilot-based channel estimation algorithm is studied, and the shortcomings of the existing algorithms are analyzed. And the wireless channel transmission characteristics are studied, and the transmission characteristics of handball are analyzed.

\section{Abbreviation}

Augmented reality (AR)

AR geometry tutorial system (argts)

\section{Competing Interests}

These no potential competing interests in our paper. And all authors have seen the manuscript and approved to submit to your journal. We confirm that the content of the manuscript has not been published or submitted for publication elsewhere.

\section{Declarations}

Ethical Approval and Consent to participate: Approved.

Consent for publication: Approved.

Availability of supporting data: We can provide the data.

\section{Author's Contributions}

All authors take part in the discussion of the work described in this paper.

\section{Fundings}

Key Project of Anhui Provincial Education Department"Study on the Handball Competition System of Universities in Anhui Province" Item No. sk2019A0487.

\section{References}

[1] Ramos A , Esslinger K . Spicing up Your Curriculum: A Seven-Day Handball Unit.. Strategies A Journal for Physical \& Sport Educators, 2016, 29(4):38-41.

[2] Fruchart E , Rulence-Paques P . Condoning aggressive behaviour in sport: A cross-sectional research in a few consecutive age categories. Journal of Moral Education, 2016, 45(1):87-103.

[3] Demitriadou E , Stavroulia K E , Lanitis A . Comparative evaluation of virtual and augmented reality for teaching mathematics in primary education. Education and information technologies, 2020, 25(1):381-401.

[4] Bili E , Mevlüt at, Resnyansky D , et al. An assessment of geometry teaching supported with augmented reality teaching materials to enhance students' 3D geometry thinking skills. International Journal of Mathematical Education in ence and Technology, 2020, 51(2):224-246.

[5] Yilmaz R M . Educational magic toys developed with augmented reality technology for early childhood education. Computers in Human Behavior, 2016, 54(1):240-248.

[6] Ying-Shao, Hsu, Yuan-Hsiang, et al. Augmented reality\%Authenticinquiry\%STEM\%STEMeducation\%STEM teaching. Research and practice in technology enhanced learning, 2017, 12(1):2-2. 
[7] Montoya Mauricio Hincapié. Evaluating the Effect on User Perception and Performance of Static and Dynamic Contents Deployed in Augmented Reality based Learning Application. Eurasia Journal of Mathematics ence\& Technology Education, 2016, 13(1):301-317.

[8] Don D. McMahon, David F. Cihak, Rachel E. Wright. Augmented Reality for Teaching Science Vocabulary to Postsecondary Education Students With Intellectual Disabilities and Autism. Journal of Research on Technology in Education, 2016, 48(1):38-56.

[9] Liou H H , Yang S J H , Chen S Y, et al. The influences of the 2D image-based augmented reality and virtual reality on student learning. Educational Technology \& Society, 2017, 20(3):110-121.

[10] Wang M , Callaghan V , Bernhardt J , et al. Augmented reality in education and training: pedagogical approaches and illustrative case studies. Journal of ambient intelligence and humanized computing, 2018, 9(5):1391-1402.

[11] Turkan Y , Radkowski R , Karabulut-Ilgu A, et al. Mobile augmented reality for teaching structural analysis. Advanced Engineering Informatics, 2017, 34(10):90-100.

[12] Chen C H , Chou Y Y , Huang C Y . An Augmented-Reality-Based Concept Map to Support Mobile Learning for Science. The Asia-Pacific Education Researcher, 2016, 25(4):567-578.

[13] Torres-Jimenez E , Rus-Casas C , Dorado R , et al. Experiences Using QR Codes for Improving the Teaching-Learning Process in Industrial Engineering Subjects. IEEE Revistalberoamericana de Tecnologias del Aprendizaje, 2018, 13(2):56-62.

[14] Smith C C , Cihak D F , Kim B , et al. Examining Augmented Reality to Improve Navigation Skills in Postsecondary Students With Intellectual Disability. Journal of Special Education Technology, 2017, 32(1):3-11.

[15] Huang Y M , Lin P H . Evaluating students' learning achievement and flow experience with tablet PCs based on AR and tangible technology in u-learning. Library Hi Tech, 2017, 35(4):00-00.

[16] Litts B K , Lewis W E. MOBILE AUGMENTED REALITY: Exploring a new genre of learning. Mobile computing and communications review, 2018, 22(3):5-9.

[17] Goehle G . Teaching with Virtual Reality: Crafting a Lesson and Student Response. The international journal for technology in mathematics education, 2018, 25(1):35-45.

[18] Chao L F , Huang H P , Ni L F , et al. [Construction and Application of Innovative Education Technology Strategies in Nursing].. Hu LI ZaZhi, 2017, 64(6):26-33.

[19] Shanbari H , Blinn N , Issa R R A . Using augmented reality video in enhancing masonry and roof component comprehension for construction management students. Engineering Construction \& Architectural Management, 2016, 23(6):765-781.

[20] Chatham-Carpenter, April. The future online: instructional communication scholars taking the lead. Communication Education, 2017, 66(4):492-494.

[21] Nandi S , Thota S, Nag A, et al. Computing for rural empowerment: enabled by last-mile telecommunications. IEEE Communications Magazine, 2016, 54(6):102-109.

[22] Pradhan R P , Arvin M B , Hall J H . Economic growth, development of telecommunications infrastructure, and financial development in Asia, 1991-2012. Quarterly Review of Economics \& Finance, 2016, 59(2):25-38.

[23] Taleb T , Mada B , Corici M I, et al. PERMIT: Network Slicing for Personalized 5G Mobile Telecommunications. IEEE Communications Magazine, 2017, 55(5):88-93.

[24] Bruneel H , Walraevens J , Maertens T . Controlling delay differentiation with priority jumps: analytical study. Numerical Algebra Control \& Optimization, 2017, 1(4):657-673.

[25] Taleb T , Mada B , Corici M I, et al. PERMIT: Network Slicing for Personalized 5G Mobile 
Telecommunications. IEEE Communications Magazine, 2017, 55(5):88-93.

\section{Method/Experiment}

The subject of this article is the current state of handball in traditional schools in our state. In our seven traditional handball schools, the subjects were 13 handball teachers (coaches) and 103 student athletes. The experimental environment is to study the use of AR applications developed based on previous surveys of AR Toolkit.The test method is to have four handball teachers (coaches) from Huaibei Haifei No. 3 Middle School and Anhui Handball Psychology School and 30 athletes from Huaibei Haifei No. 3 Middle School and Keck Middle School fill in the questions together. Three weeks later, they repeated the same question and calculated the correlation coefficient $\mathrm{R}$ for comparison.

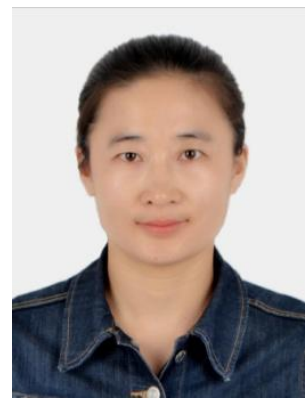

Qin Fan was born in Suzhou, Anhui Province.China, in1980. She received her master's degree from Shanghai University of Sport, China, works at Anhui University of Finance and Economics. Her research interest includes sport economics.

E-mail: 120081598@aufe.edu.cn

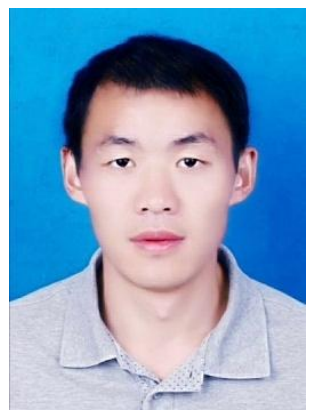

Deying Li was born in Suzhou, Anhui Province.China, in1979. He received his master's degree from Shanghai University of Sport, China, works at basic department of Anhui Vocational College of Press and Publishing. His research interest includes sport economics.

E-mail:2004050115@ahcbxy.edu.cn 


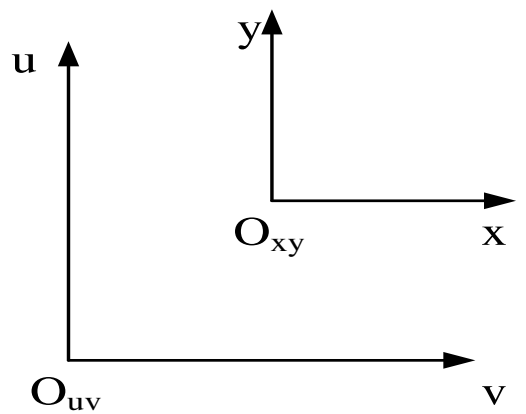

Photogrammetry

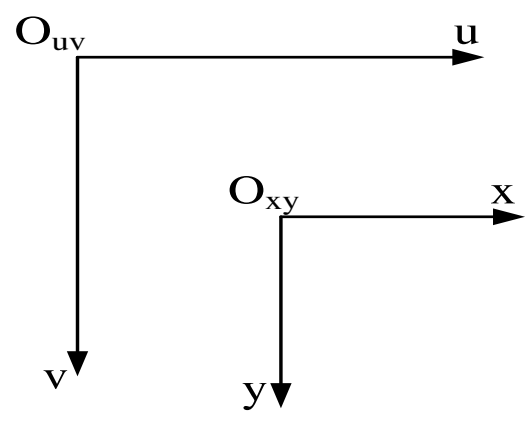

Computer Vision

Figure 1. Image coordinate system in photo grammetry and computer vision

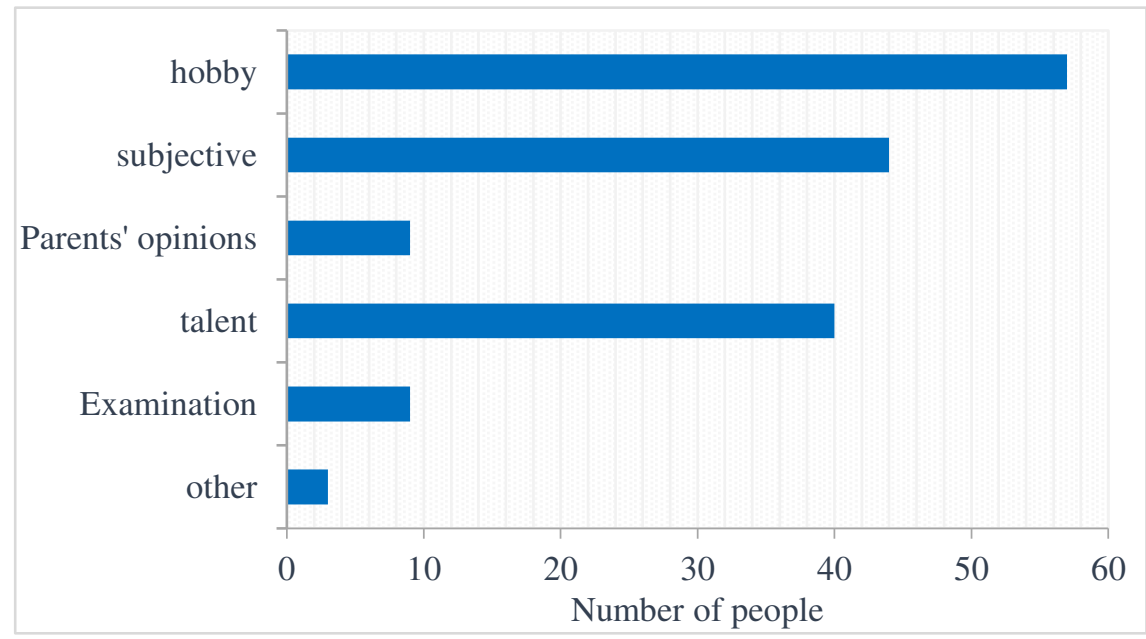

Figure 2. Statistics of athletes' motivation in sports training 


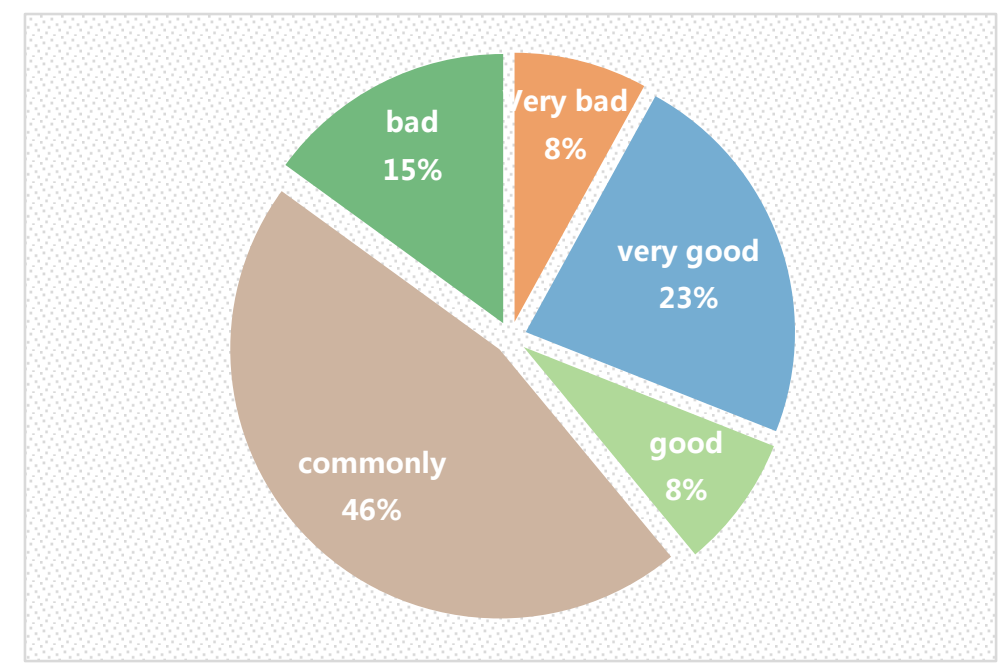

Figure 3. Quality statistics of training sites

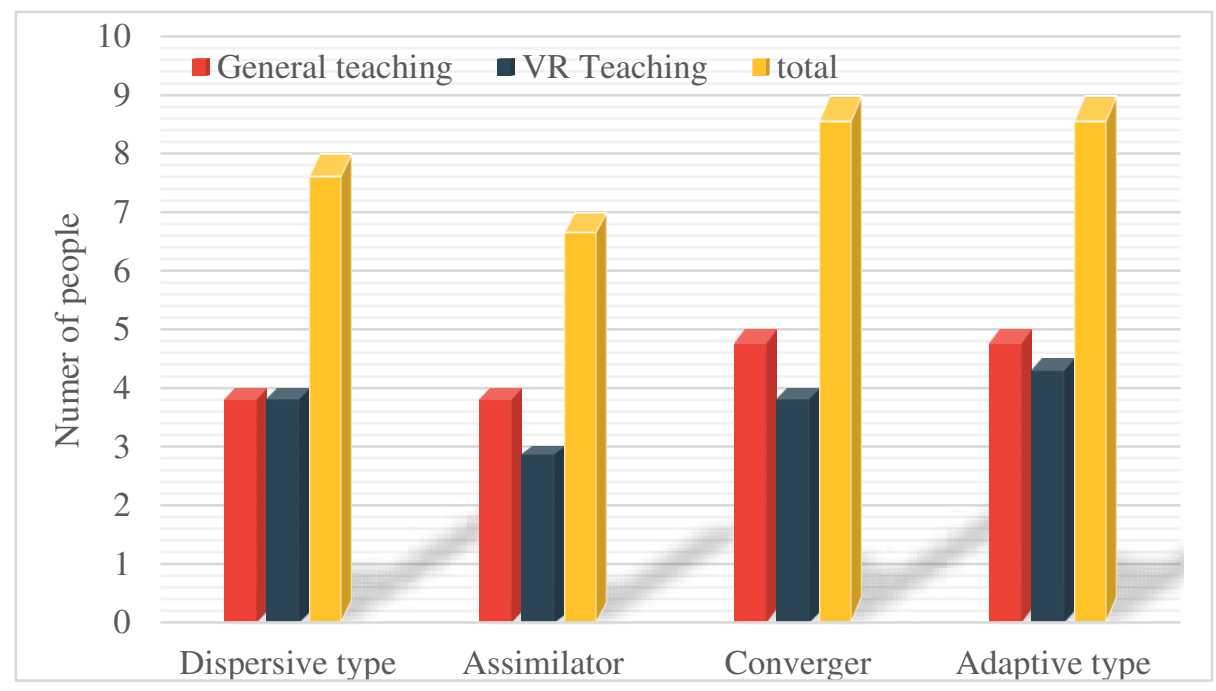

Figure 4. Experimental situation

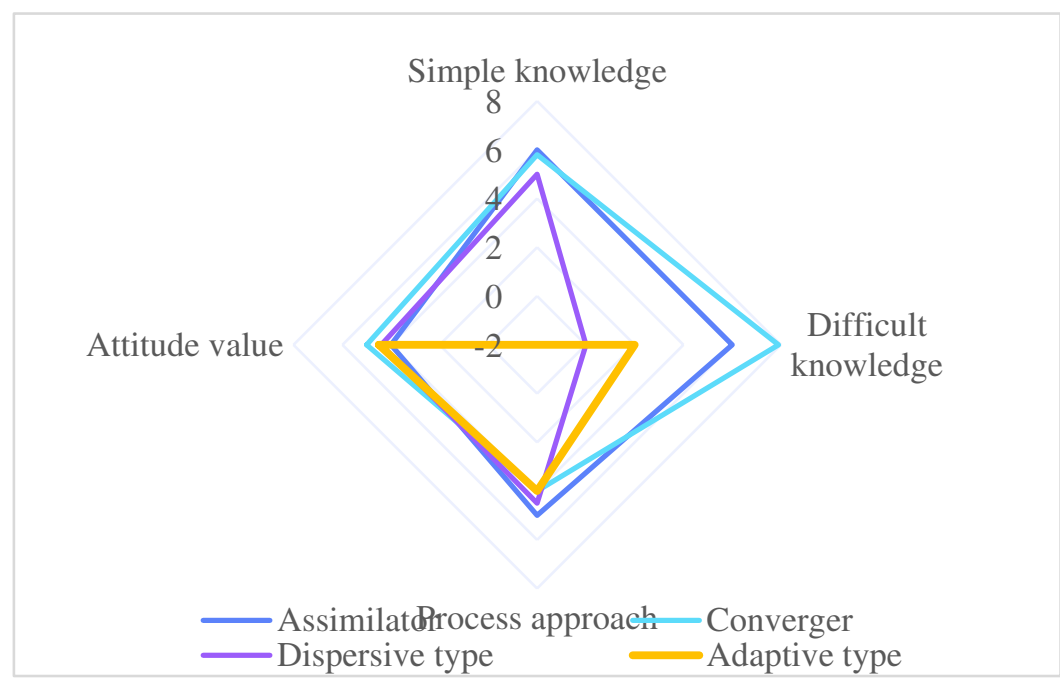

Figure 5. Radar chart of teaching effect 


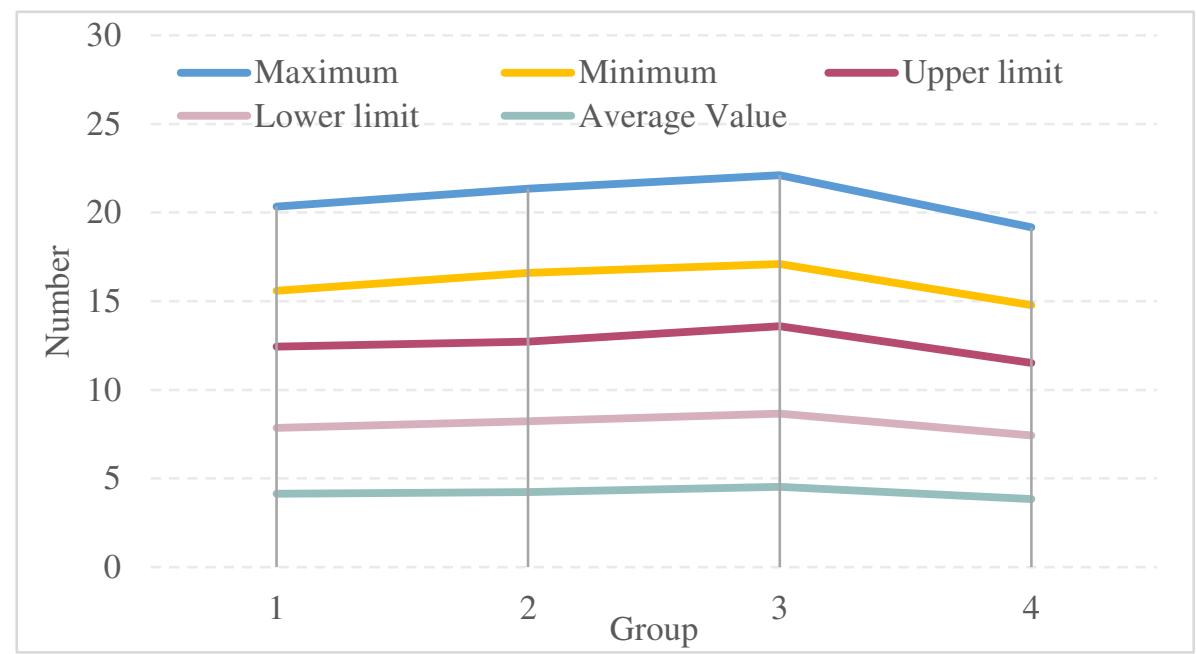

Figure 6. Effectiveness of knowledge and skills learning

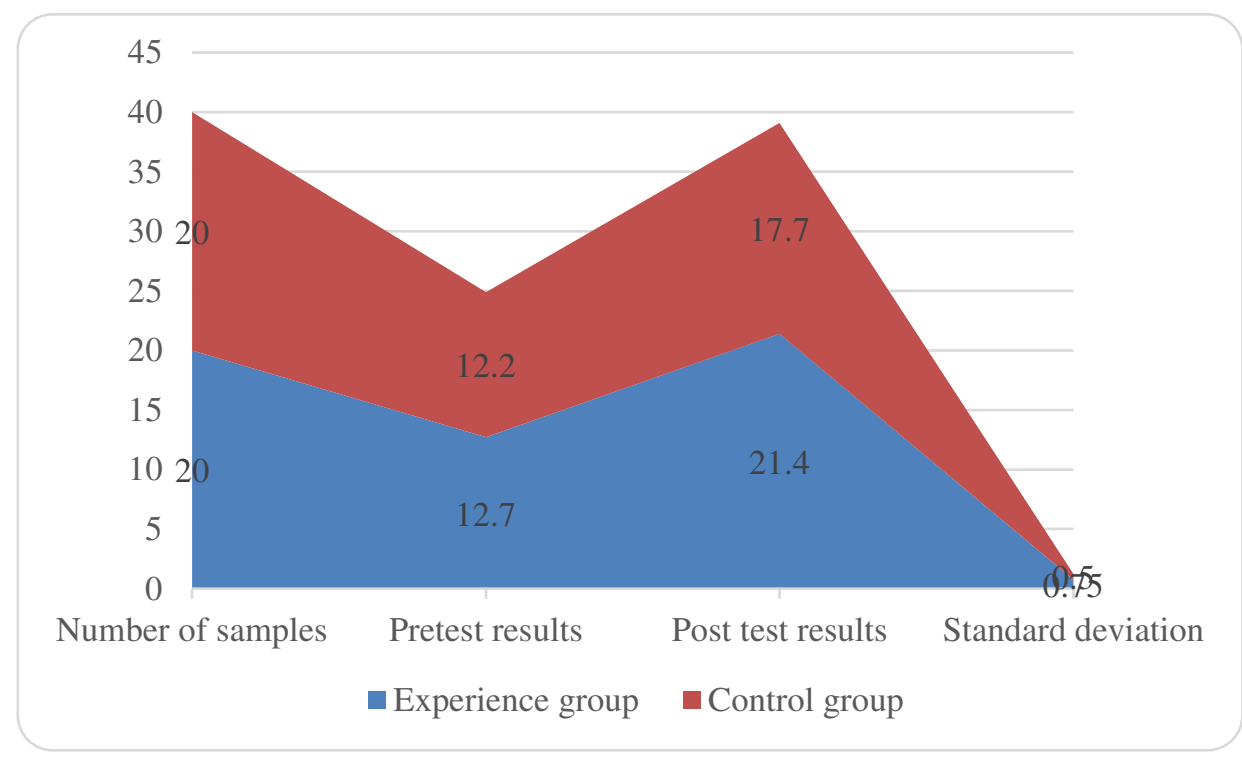

Figure 7. Comparison of experimental results 
Figures

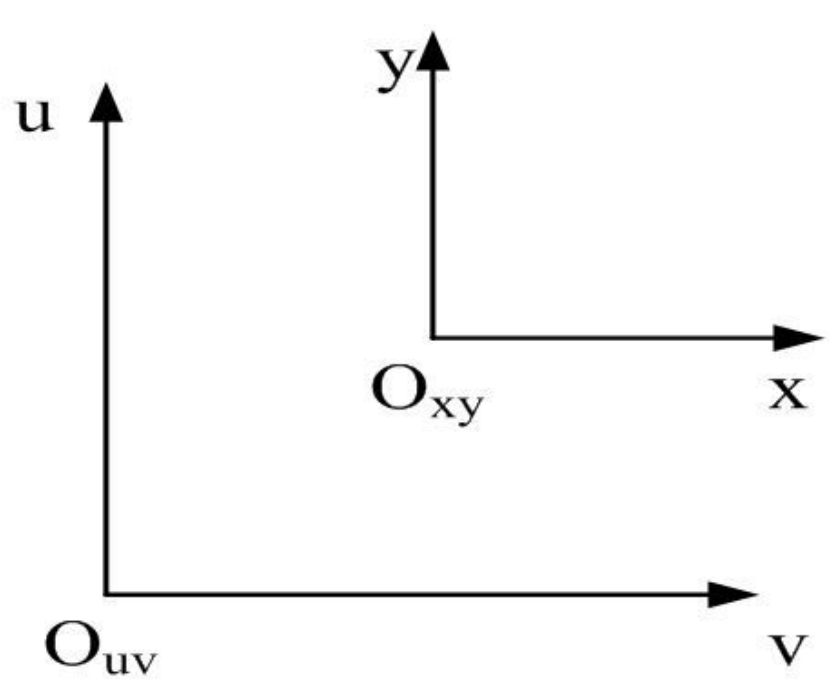

\section{Photogrammetry}

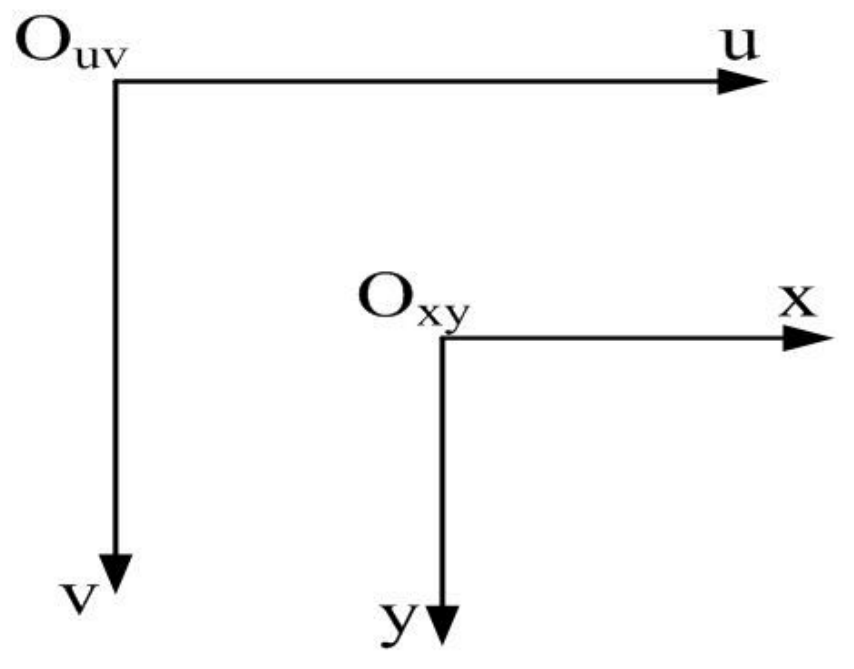

Computer Vision

Figure 1

Image coordinate system in photo grammetry and computer vision

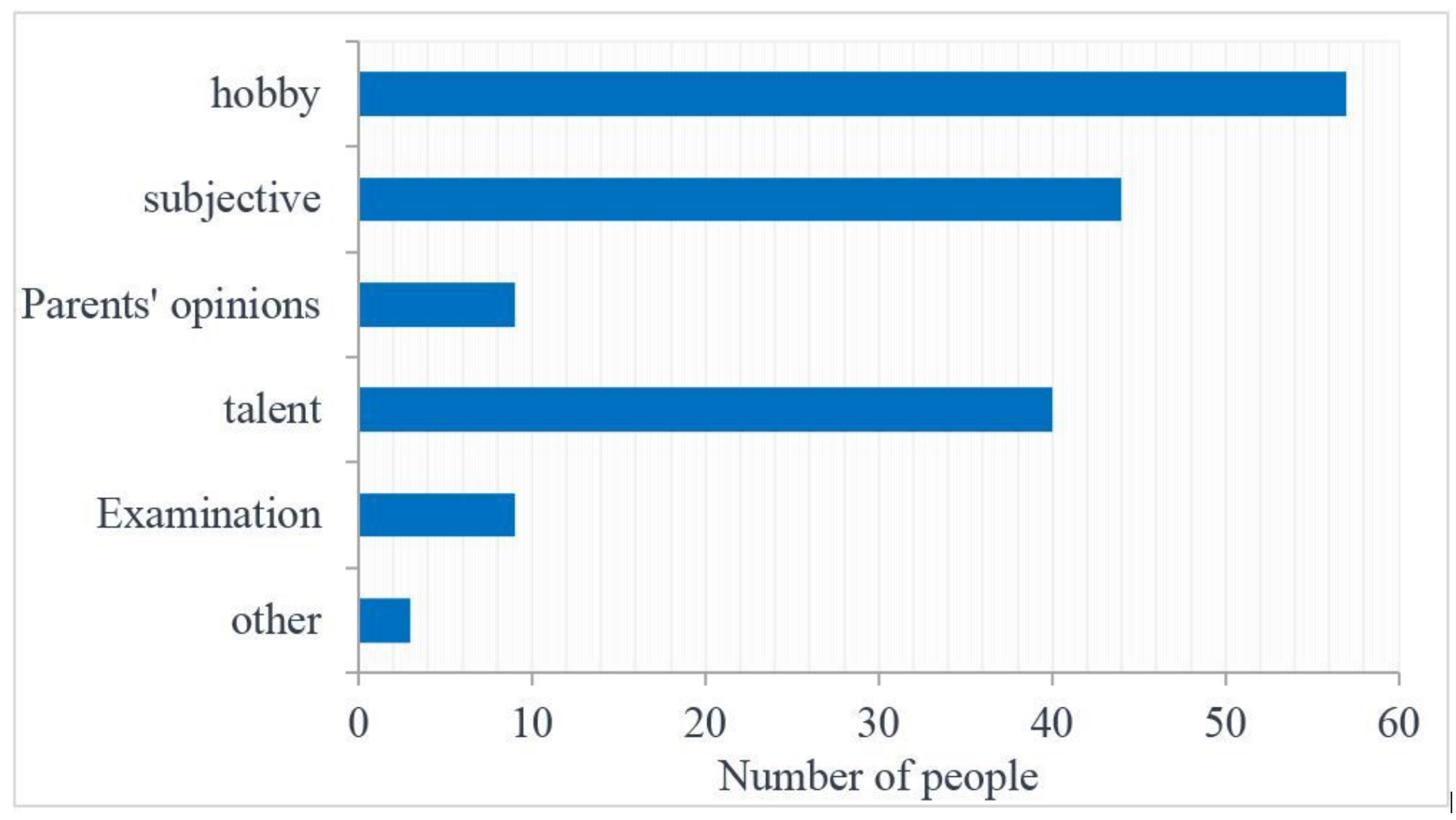

Figure 2 
Statistics of athletes' motivation in sports training

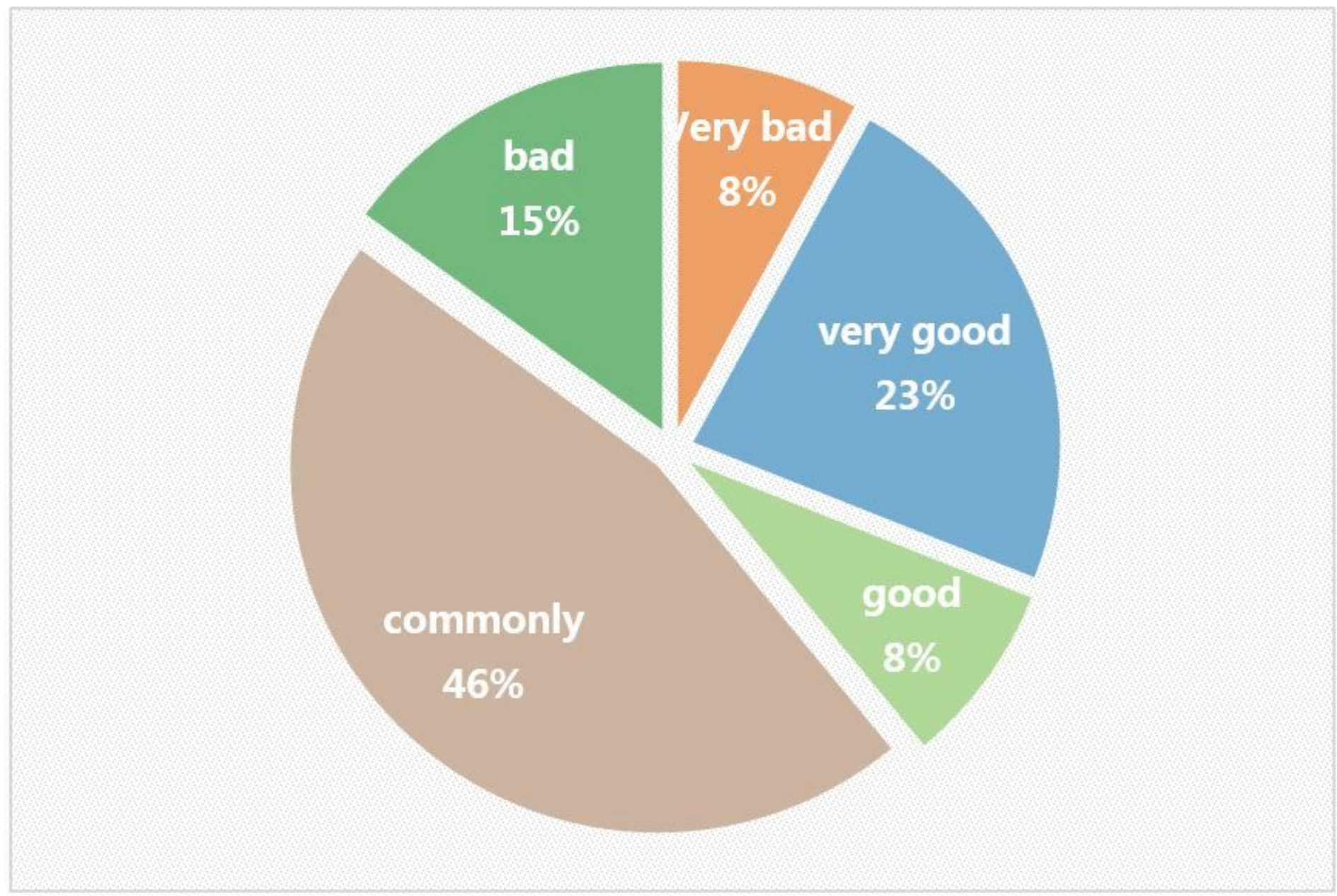

Figure 3

Quality statistics of training sites 


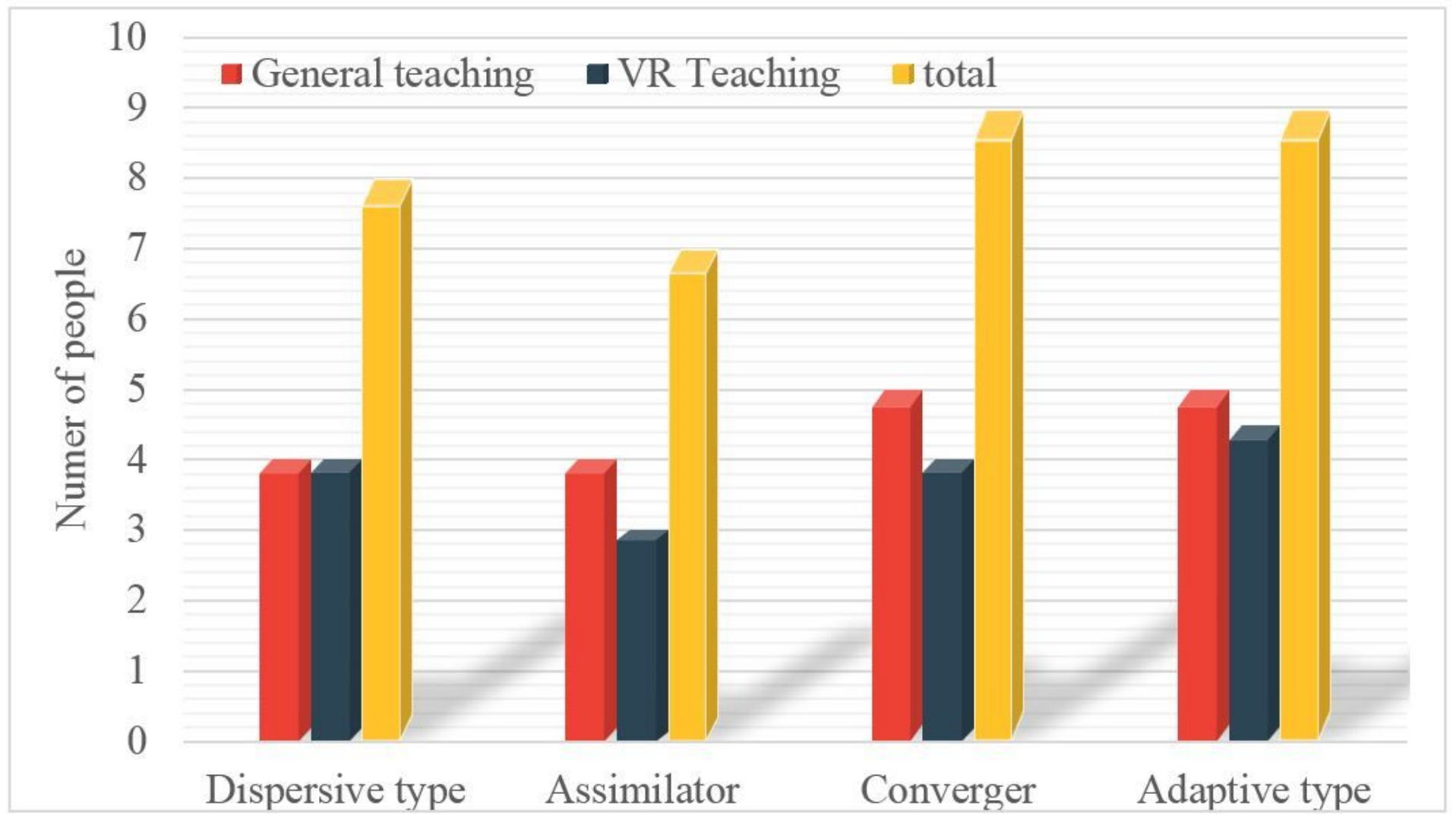

Figure 4

Experimental situation 


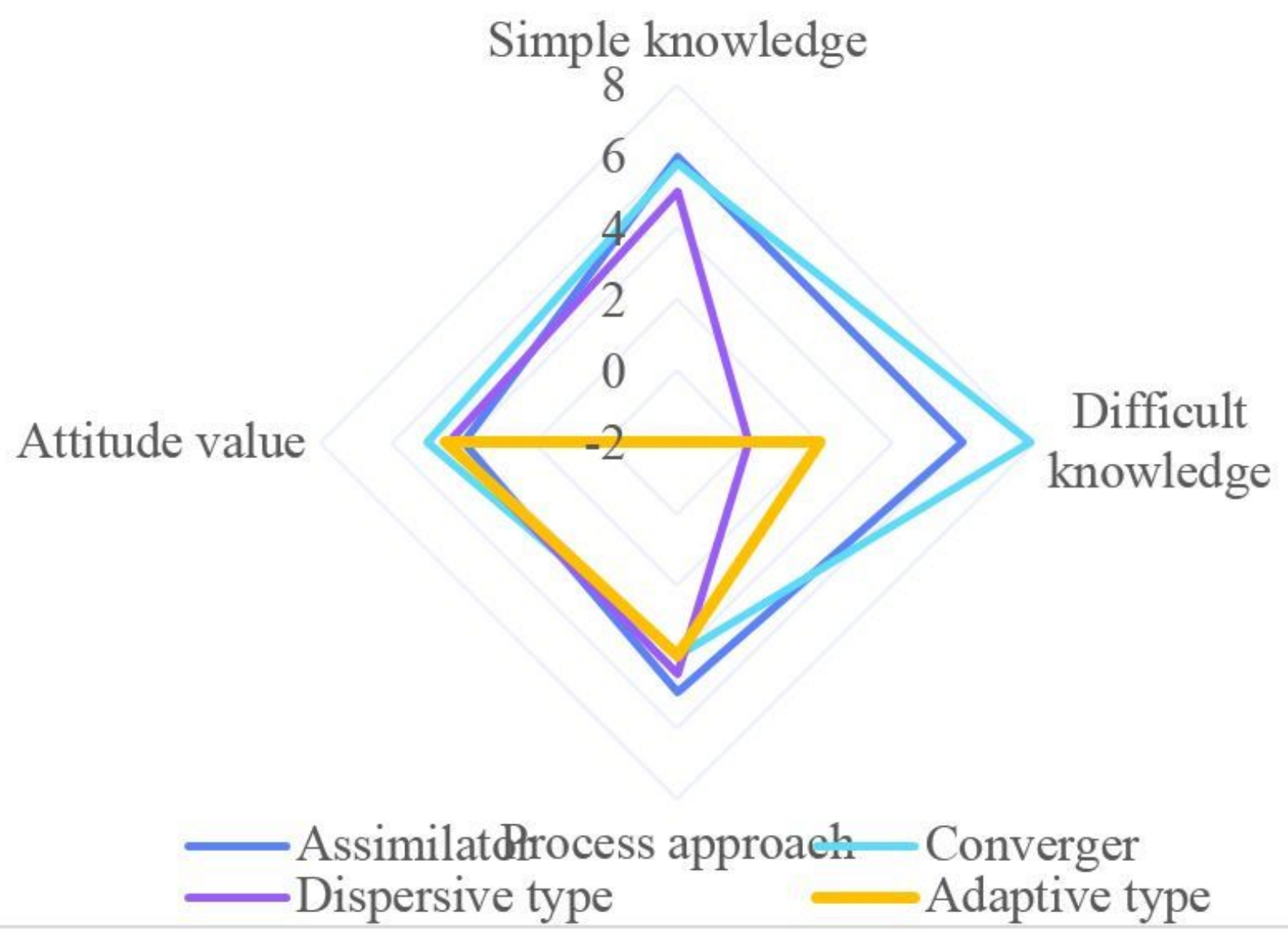

Figure 5

Radar chart of teaching effect 


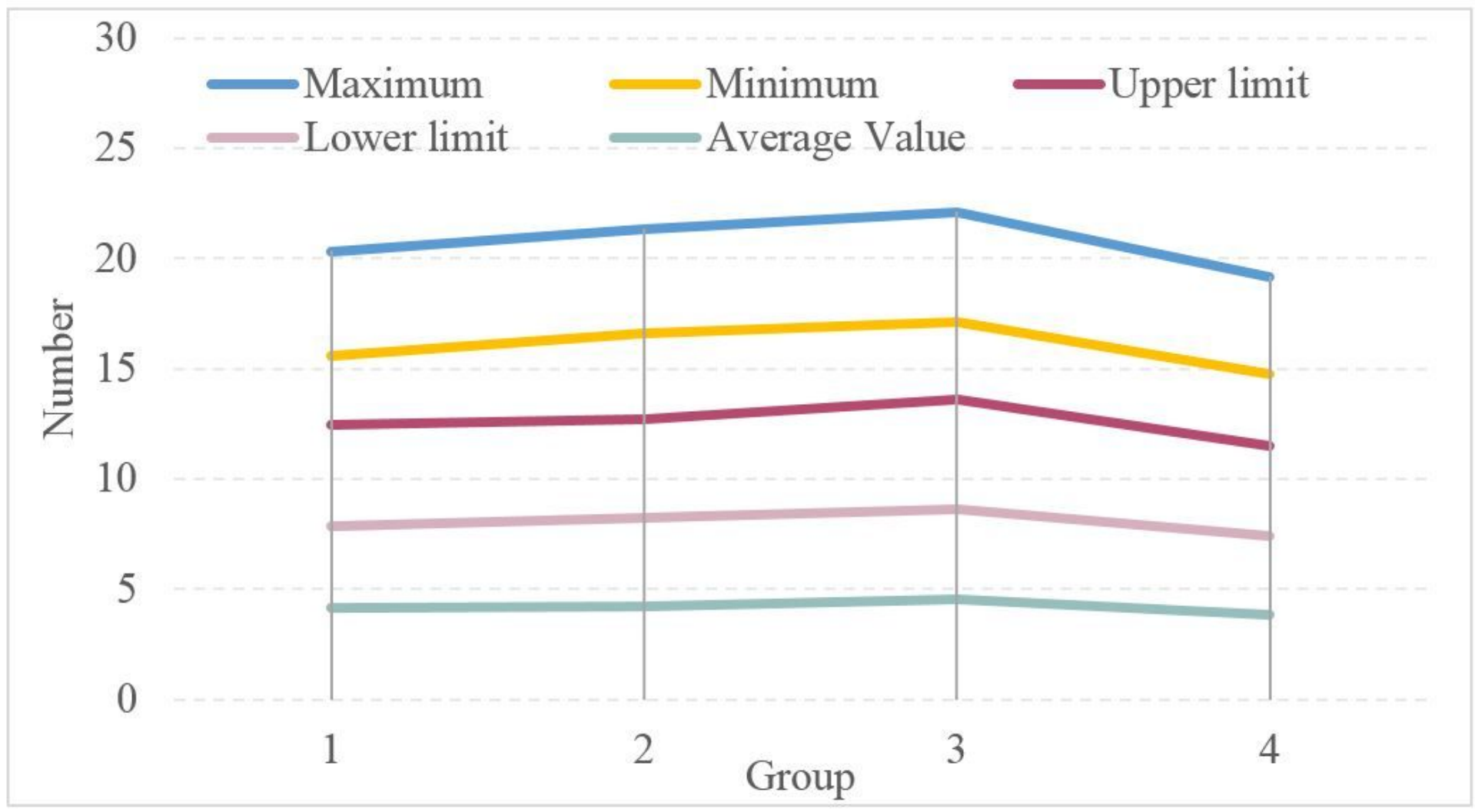

\section{Figure 6}

Effectiveness of knowledge and skills learning

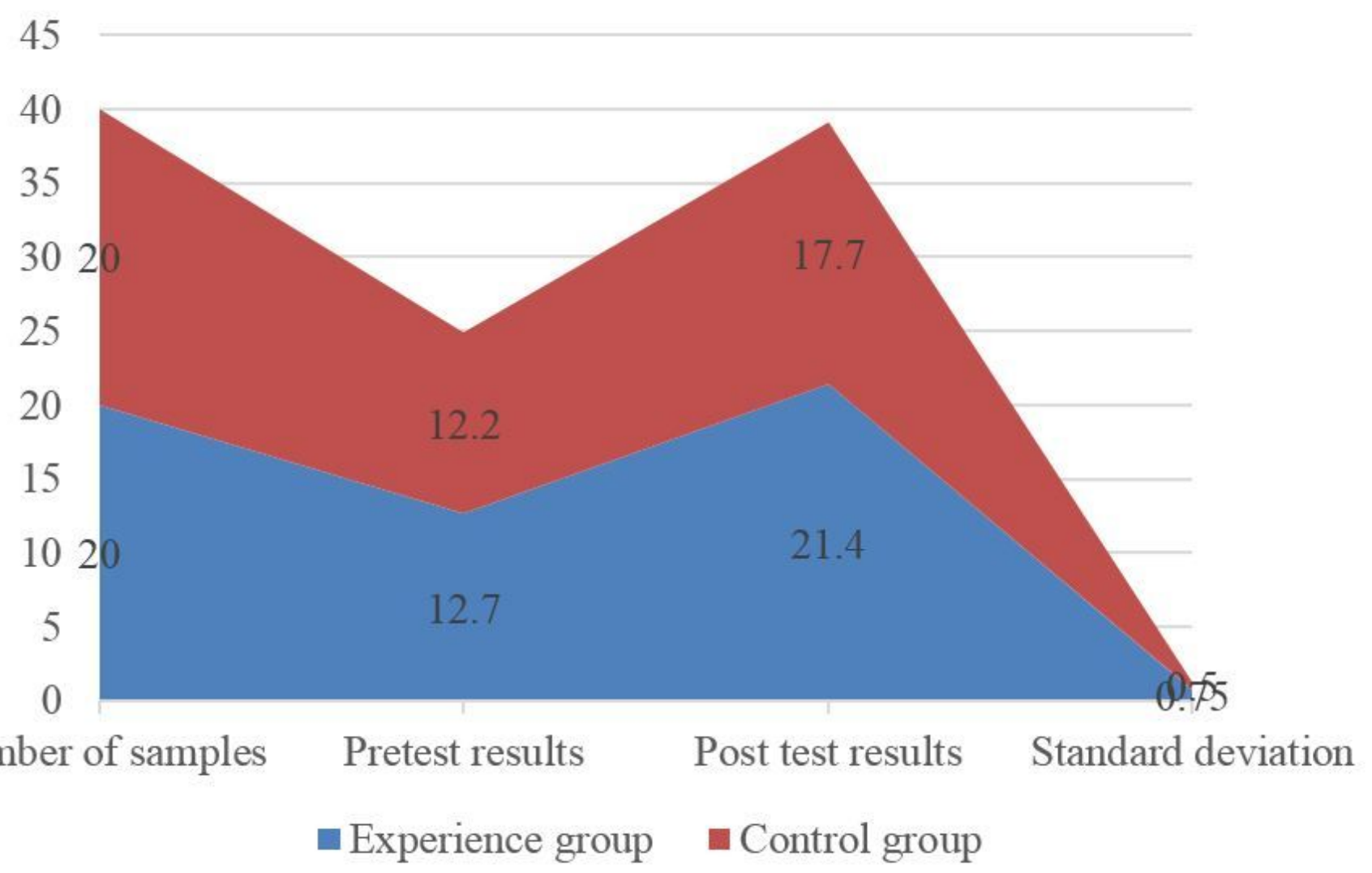


Figure 7

Comparison of experimental results 